\title{
FEDSM2008-55281
}

\section{NUMERICAL STUDY OF SMOKE PROPAGATION IN A SIMULATED FIRE IN A WAGON WITHIN A SUBWAY TUNNEL}

\author{
Felipe Vittori \\ Simón Bolívar University \\ Department of Mechanics \\ Caracas, Venezuela \\ 0235559@usb.ve
}

\author{
Luis Rojas-Solórzano \\ Simón Bolívar University \\ Department of Energy \\ Conversion \\ Caracas, Venezuela \\ rrojas@usb.ve
}

\author{
Armando J. Blanco \\ Simón Bolívar University \\ Department of Mechanics \\ Caracas, Venezuela \\ ajblanco@usb.ve
}

\author{
Rafael Urbina \\ Simón Bolívar University \\ Department of Process \\ and Systems \\ Caracas, Venezuela \\ rurbina@usb.ve
}

\begin{abstract}
This work deals with the numerical (CFD) analysis of the smoke propagation during fires within closed environments. It is evaluated the capacity of the emergency ventilation system in controlling the smoke propagation and minimizing the deadly impact of an eventual fire in a wagon within the Metro de Caracas subway tunnel on the passengers safety. For the study, it was chosen the tunnel section between Teatros and Nuevo Circo subway stations, which consists of two parallel independent twin tunnels, connected through a transverse passage. The tunnels are provided by a longitudinal ventilation system, integrated by a set of reversible fans located at both ends of the tunnels.
\end{abstract}

Three stages were considered in the study: (a) Model set up; (b) Mesh sensitivity analysis; (c) Validation of the physicalnumerical parameters to be used in the numerical model; and (d) Simulation of fire scenarios in Metro de Caracas subway stations. Stages (b)-(c), aimed to testing and calibrating the CFD tool (ANSYS-CFX10 ${ }^{\mathrm{TM}}$ ), focused on reproducing experimental data from Vauquelin and Mégret [1], who studied the smoke propagation in a fire within a 1:20 scale road tunnel. Stage (d) critical scenarios were established via a preliminary discussion with safety experts from Metro de Caracas, in order to reduce the computer memory and the number of simulations to be performed. The analyses assessed the reliability of escape routes and alternative paths for the evacuation of passengers. Additionally, the smoke front movement was particularly computed, as a function of time, in order to determine the possible presence of the "backlayering" phenomenon [5].

Results demonstrate the strengths and weaknesses of the current ventilation system in the event of a fire in the subway tunnel, and suggest new strategies to address this potentially lethal event to minimize the risks for passengers.

\section{NOMENCLATURE}

$\mathrm{U}$ velocity vector,

$\rho$ fluid density

$\mathrm{t}$ time

p pressure

g gravity acceleration

$\mu$ viscosity

$\mu_{\text {effec }}$ effective viscosity

$\delta$ identity matrix

$\mathrm{S}_{\mathrm{M}}$ source term of momentum

$\mathrm{S}_{\mathrm{E}}$ source term of energy equations

$\mathrm{h}$ total specific enthalpy

$\lambda$ thermal conductivity

T temperature

$\mathrm{P}$ turbulence production due to viscous and buoyancy forces

$\mathrm{C}_{\varepsilon 1}, \mathrm{C}_{\varepsilon 2}, \sigma_{\varepsilon}$ and $\sigma_{\mathrm{k}}$ constants of the turbulence model

$\mathrm{Q}_{\text {EXT }}$ mass flow rates of smoke extracted by the ventilation

$\mathrm{Q}_{\mathrm{SMOKE}}$ mass flow rates of the smoke source

$\varepsilon$ ventilation system efficiency

\section{INTRODUCTION}

A series of fires in road and train tunnels, like the one occurred in Mont Blanc tunnel in 1999, with approximately 40 victims, marked the beginning of the in-depth study of emergency and safety systems of many road and train tunnels in the world. These studies have thrown quite interesting and useful results on how to help in fighting fires within closed spaces, especially in ventilation systems operating to control the smoke being generated.

A wide variety of analyses have arisen. Among those, it is important to mention the experimentation in actual-scale 
tunnels, like the "Memorial Tunnel" in the United States, which is a $853 \mathrm{~m}$-long highway tunnel, with a section of $4.3 \mathrm{~m}$-high by $7.3 \mathrm{~m}$-wide [10]. Its structure might support several ventilation schemes, holds a variety of instruments (gas velocity, temperature, etc.) and is provided with data acquisition systems. The fires are simulated using open fuel tanks, which are burned and thus, it is possible to represent the diverse fire sources that might be considered.

Nevertheless, due to the high experimental costs, both in actual- and reduced-scale experiments, the numerical simulations via CFD (Computational Fluid Dynamics) arise as an important complementary tool in these analyses. This new tendency has been developing and improving altogether with the computational field (hardware and software) in such a way that computational simulations have become an everyday tool delivering a more economic and effective mean to address this type of problems.

Regarding to human lives endangered during a fire, the most important issue in assuring the people integrity is related to considering that in a fire the greater cause of death is by asphyxia or inhalation of toxic gases like $\mathrm{CO}$ and $\mathrm{CO}_{2}$. On this very important fact lies the importance of the ventilation systems, which in turn must be able to dilute or remove the smoke clouds, while allowing a safer evacuation route.

\section{DEVELOPMENT OF SMOKE TRAIL}

In a common fire, it is known that the smoke ascends and expands in all directions as a gas usually does. Nevertheless, in a tunnel the hot smoke travels upwards and longitudinally since it is limited by the enclosure boundaries. Moreover, the tunnel slope plays an important role because it generates a longitudinal component of the buoyancy and extends the smoke in a longitudinal direction. In the design of emergency ventilation systems, the concept of "critical velocity" represents the air speed necessary to move the mass of smoke within the tunnel in the target direction. For practical purposes, this velocity is currently determined by means of empirical correlations. When the speed of the ventilated air is below the critical value, then there happens the so called "backlayering" phenomenon [5].

\section{GOVERNING EQUATIONS}

The CFD analysis is based on the numerical solution of the fluid motion, heat transfer and species concentration equations, also named as the governing equations in the analytical study of the phenomenon. Therefore, turbulent models, along with the time-averaged governing equations, have arisen as a manner of approximating the average effects of turbulence, yet using a number of nodes compatible with current hardware and software. Among all the turbulent models, the $\mathrm{k}-\varepsilon$ model, based on the transport differential equations of the turbulent kinetic energy and dissipation, respectively, has become the standard in engineering applications of flows within closed conducts[8]. Therefore, in the current analysis that is the adopted turbulent model. In summary, the governing equations considered in this study are:

- Continuity:

$$
\nabla \bullet U=0
$$

- Momentum:

$$
\frac{D(\rho U)}{d t}=\nabla p+\mu \nabla^{2} U+\rho \beta\left(T-T_{r e f}\right)+S_{M}
$$

- Energy:

$$
\frac{\partial \rho h}{\partial t}-\frac{\partial p}{\partial t}+\nabla \bullet(\rho U h)=\nabla \bullet(\lambda \nabla T)+S_{E}
$$

- Turbulent kinetic energy (k):

$$
\frac{\partial(\rho k)}{\partial t}+\nabla \bullet(\rho U k)=\nabla \bullet\left[\left(\mu+\frac{\mu_{t}}{\sigma_{k}}\right) \nabla k\right]+P_{k}-\rho \varepsilon
$$

- Turbulent dissipation ( $\varepsilon$ ):

$$
\frac{\partial(\rho \varepsilon)}{\partial t}+\nabla \bullet(\rho U \varepsilon)=\nabla \bullet\left[\left(\mu+\frac{\mu_{t}}{\sigma_{\varepsilon}}\right) \nabla \varepsilon\right]+\frac{\varepsilon}{k}\left(C_{\varepsilon 1} P_{k}-C_{\varepsilon 2} \rho \varepsilon\right)
$$

Meaning of special symbols may be found in the Nomenclature.

The fire source was simulated as a volumetric entry of smoke and heat. I.e., combustion reaction will not be modeled to reduce the computational cost. Additionally, due to the smoke homogenous nature and its miscibility in air, the fluid that will represent the smoke or $\mathrm{CO}$ can be thought as a species that spreads in the air, and therefore, its concentration (ø) might be modeled by the conservation of species equation:

- Species transport:

$\frac{\partial \phi}{\partial t}+\nabla \bullet(U \phi)=\nabla \bullet\left(\left(\rho D_{\phi}+\frac{\mu_{t}}{S c_{t}}\right) \nabla \bullet\left(\frac{\phi}{\rho}\right)\right)+S_{\phi}$

The radiation heat transfer was not considered since its effect on the smoke propagation has proven to be limited to a relatively small fraction of the tunnel length around the fire source[8].

As mentioned before, the analytical solution of this set of equations, subject to appropriate boundary and initial conditions, becomes quite difficult if not impossible, and therefore, numerical methods are used in order to facilitate an approximate solution. The finite volume-based finite element method is used, for which the derivatives are treated providing second-order numerical schemes for both space (higher-order upwind for the advective term and centered differences for the rest) and time (Euler-Backward). The resulting set of algebraic equations is solved in a coupled and iterative way. 


\section{MESH SENSIVITY AND VALIDATION ANALYSIS}

There are previous studies on the simulation of smoke propagation in closed spaces by means of similar numerical techniques and calculation tool (ANSYS-CFX) as those proposed in this work [4]. However, further testing and validation were performed as part of this research by running simulations of the smoke propagation in a numerical model and its comparison with data taken from the respective 1:1 experimental tunnel.

During the validation procedure, a mesh sensitivity analysis was carried out in order to reduce the computational cost of subsequent simulations; i.e., the larger mesh element sizes, yet able to capture the main features of the smoke propagation, were used as much as possible. The mesh was built up by tetrahedral and prismatic elements which are of common use in numerical simulations because of their versatility and simplicity of implementation in complex geometries.

Thus, the objective of this phase of the work was to reproduce reasonably the experimental results published by Vauquelin and Mégret [1]. In their paper, the authors present the experimental study of the effects caused by the shape, position and orientation of the ventilation grids located on the ceiling and walls of a highway tunnel. In addition, they calculated the ventilation system efficiency based on the amount of smoke withdrawn by the fans through the grids versus the amount of smoke that escapes through the tunnel extremes:

$$
\varepsilon=\frac{Q_{E X T}}{Q_{S M O K E}}
$$

That article also shows the way of simulating the smoke generating from a car, motorcycle or bus fire. In a 1:1 scale experiment, an open container filled with fuel is typically used; however, Vauquelin and Mégret [1] performed their experiments on a 1:20 scale tunnel that was actually $200 \mathrm{~m}$ long, 10m-wide and 5m-high. Therefore, their experiment's fire source was also scaled and the smoke was substituted by a mixture of helium and air, and empirical correlations were used to translate them into smoke. Table 1 presents the boundary and fire source data used for the validation of the numerical model used in that work and Figure 1 shows the geometry of the tunnel.

Table 1. Boundary and source conditions

\begin{tabular}{|c|c|c|c|c|l|}
\hline $\begin{array}{c}\text { Heat } \\
\text { intensity }\end{array}$ & $\begin{array}{c}\text { Source } \\
\text { diameter }\end{array}$ & $\begin{array}{c}\text { Smoke } \\
\text { flow rate }\end{array}$ & $\begin{array}{c}\text { Source } \\
\text { temperature }\end{array}$ & $\begin{array}{c}\text { Extraction } \\
\text { velocity }\end{array}$ & Flow ratio \\
\hline \hline $1 \mathrm{MW}$ & $0.98 \mathrm{~m}$ & $5.8 \mathrm{~m}^{3} / \mathrm{s}$ & $267^{\circ} \mathrm{C}$ & $0.36 \mathrm{~m} / \mathrm{s}$ & $2 \mathrm{Q}_{\mathrm{t}}=0.5 \mathrm{Q}_{\mathrm{s}}$ \\
\hline
\end{tabular}

$Q_{t}$ extractor flow rate, $Q_{s}$ source flow rate

In our numerical sensitivity and validation exercise, using Vaquelin and Mégret data, four different grids were used:

- Mesh A: Coarse grid, $0,5 \mathrm{~m}$ of element size.
- Mesh A1: A variation of mesh A. In some regions, like extraction duct and fire source, the mesh is likely to be denser in order to capture the larger gradients.

- Mesh B: is a coarse mesh of $2 \mathrm{~m}$ size element and had some areas with a denser grid like the A1 mesh.

- Mesh C: Is the one with the smallest size of element everywhere, which in turn is expected to deliver the larger accuracy among all.

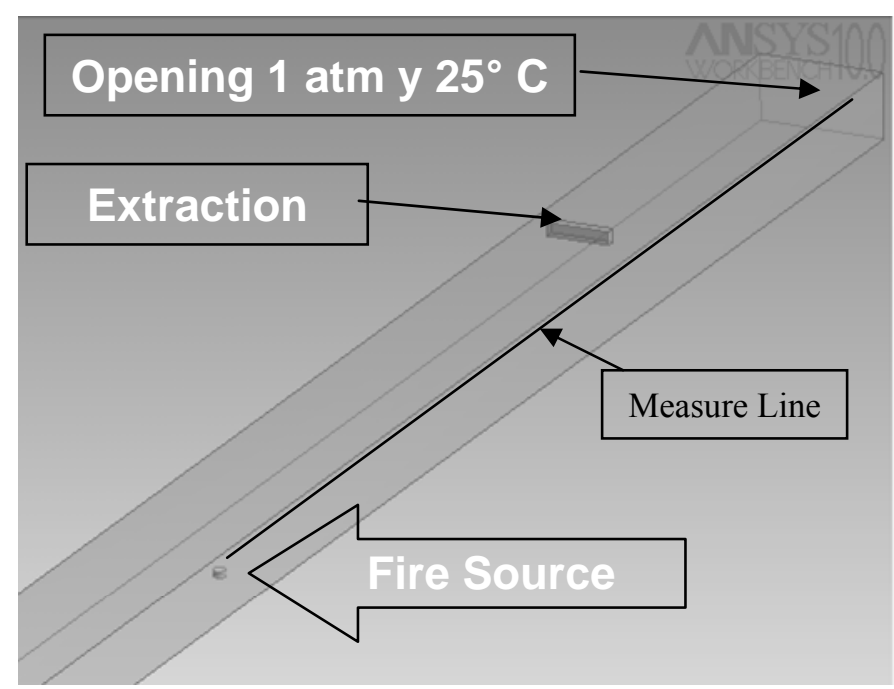

Figure 1. Computational geometry of the experimental tunnel in actual scale [1]. Because of the symmetry, it is shown only one exit of the tunnel and a measure line to retrieve the temperature profile, which is $4 \mathrm{~m}$ above the source.

Figure 2 depicts the temperature variations attributed to mesh coarseness. The $2 \mathrm{~m}$-tetrahedral mesh demonstrated to capture the important features of the thermal phenomena and provided easiness of calculations since it required less time than the other meshes. Therefore, this mesh was adopted in further simulations.

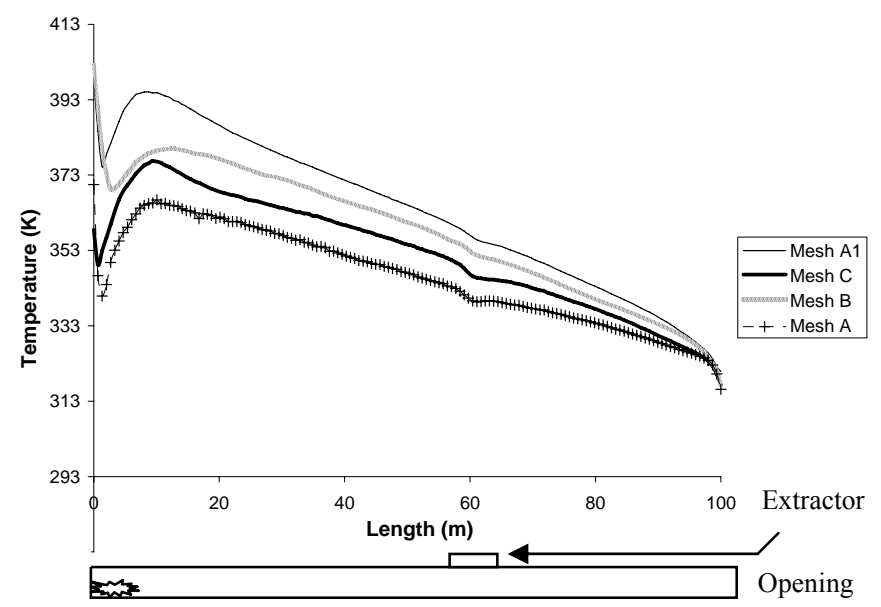

Figure 2. Longitudinal temperature profiles from the source $(0 \mathrm{~m})$ to the opening $(100 \mathrm{~m})$. 
Results obtained for tetrahedral grids of $2 \mathrm{~m}$ and $0.5 \mathrm{~m}$ are compared with experimental results, basically on the efficiency obtained by Vauquelin and Mégret [1].

Table 2. Efficiency of ventilation system: comparison of experimental and numerical results.

\begin{tabular}{|c|c||c|c|}
\hline \multirow{2}{*}{$\begin{array}{c}\text { Ventilation } \\
\text { system } \\
\text { efficiency }\end{array}$} & Vauquelin and Mégret & \multicolumn{2}{|c|}{ Numerical result } \\
\cline { 2 - 4 } & $13 \%$ & Dense grid $2 \mathrm{~m}$ & Dense grid $0.5 \mathrm{~m}$ \\
\cline { 3 - 4 } & & $13.56 \%$ & $13.53 \%$ \\
\hline
\end{tabular}

Comparisons between experimental data and numerical calculations are presented in table 2 . The differences between experimental and numerical results are around 4\%. Results related to the temperatures, each $20 \mathrm{~m}$ from the source to the opening, not shown here, were found to be around $7 \%$. Therefore, the error associated to the model and mesh were bounded under $10 \%$, and since both grids led to results very close to experimental data, it validated our choice of the $2 \mathrm{~m}$ tetrahedral grid for further simulations on the actual case of interest (tunnel of Metro de Caracas).

\section{CASE OF STUDY: METRO DE CARACAS SUBWAY TUNNEL. COMPUTATIONAL GEOMETRY}

The analysis of the smoke propagation, which motivated this investigation, is performed on the section Teatros-Nuevo Circo of Metro de Caracas subway network. This section represents a very good choice for a CFD pilot project in Caracas subway because it is one of its shortest lines $(700 \mathrm{~m})$. It might be considered as a straight sector since it has a very large radius of curvature. Additionally, since it is one of the newest sections, it is provided with plenty of first hand blue prints for the creation of the numerical model. This tunnel is provided by a longitudinal induced ventilation system, with fans placed on both extremes. In the current analysis, there will be three fans at Teatros, in injection mode, and two fans at Nuevo Circo, in extraction mode. Under the explored conditions, one of the main challenges rests on determining the capability of the induced ventilation to overcome the natural buoyant draft in case of a fire originated in a wagon within the tunnel.

The case scenario hypotheses are as follows: (a) Fire is caused by an electrical failure in the wagon's underneath power-box, (b) The train stops in the mid-point between Teatros' station and the transversal pass-way (indicated in Figures 3 and 4), (c) The wagon in fire, is located in the middle of the train, (d) Users evacuation occurs in both directions of the tunnel and; (e) Air stream produced by the train piston effect is negligible. The source condition was completed with data from semiempirical models of Vauqueline and Megret [1] and fire data from materials of the Metro de Caracas train. Values of the source condition are in table 3.
Table 3. Source and boundary condition

\begin{tabular}{|c|c||c||c|c|c|}
\hline $\begin{array}{c}\text { Heat } \\
\text { intensity }\end{array}$ & $\begin{array}{c}\text { Source } \\
\text { diameter }\end{array}$ & $\begin{array}{c}\text { Smoke } \\
\text { flow rate }\end{array}$ & $\begin{array}{c}\text { Source } \\
\text { temperature }\end{array}$ & $\begin{array}{c}\text { Mass flow } \\
\text { Teatros fan. }\end{array}$ & $\begin{array}{c}\text { Mass flow Nuevo } \\
\text { Circo fan }\end{array}$ \\
\hline \hline $12 \mathrm{MW}$ & $2,7 \mathrm{~m}$ & $53,6 \mathrm{~m}^{3} / \mathrm{s}$ & $452,5^{\circ} \mathrm{C}$ & $97,87 \mathrm{~kg} / \mathrm{s}$ & $83,89 \mathrm{~kg} / \mathrm{s}$ \\
\hline
\end{tabular}

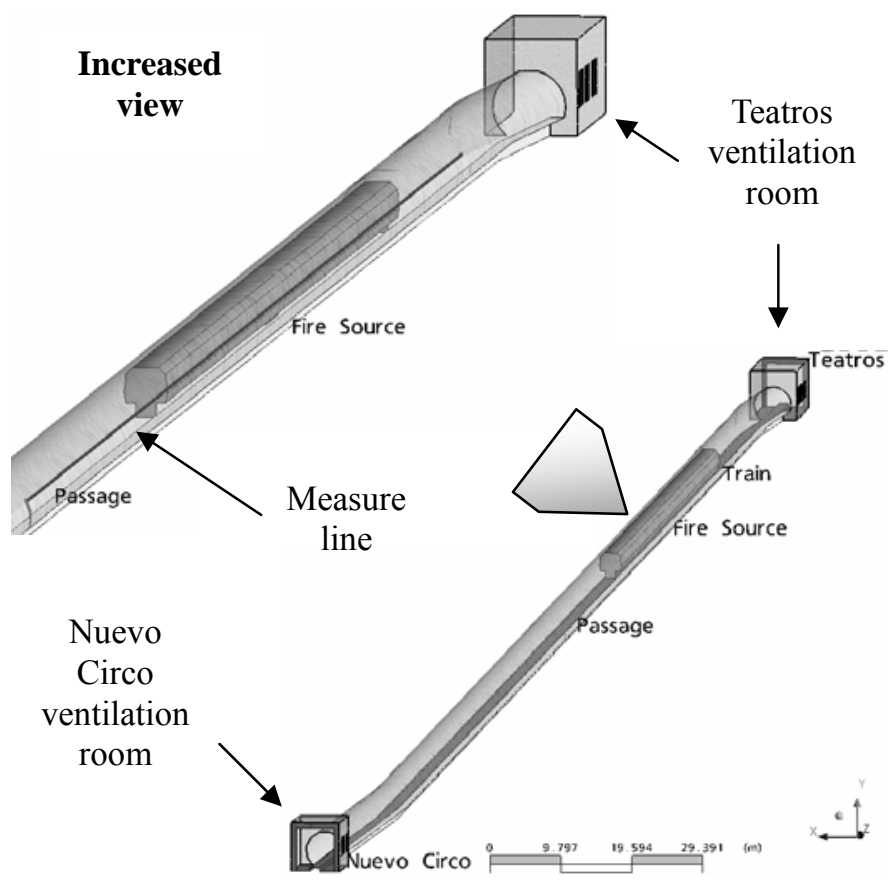

Figure 3. Computational geometry of Teatros-Nuevo Circo section. The measure line is $1.70 \mathrm{~m}$ above the escape floor and extends $20 \mathrm{~m}$ from the last rail.

Because the security and integrity of the passengers are the most important objective of the emergency ventilation, the results about temperature and smoke will be referred to the escape walkway, which is a footbridge next to the train.

Due to uncertainty, because there is not enough information about the actual condition existing within the passengers station (the imaginary end of the computational domain) and how this condition might affect the flow patterns within the fan rooms, there will be a boundary condition that regulates the amount of air that could be expelled out of the tunnel and into the external (imaginary or not included in the analysis) station. In the portal of Nuevo Circo, it was used a boundary condition that allows the fan to extract some volume of air from the station.

Therefore, simulations with restrictions of $25 \%, 50 \%$ and $75 \%$ of mass flow allowed to escape through the portal of Teatros towards the passenger railway were considered as shown in figure 4 . 


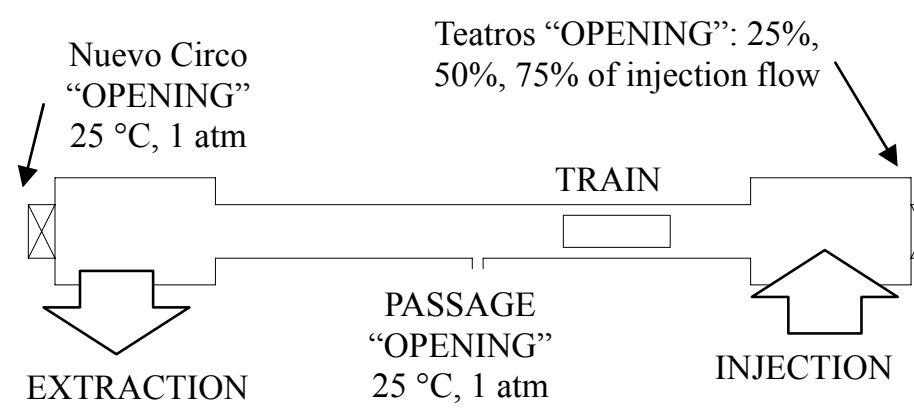

Figure 4. Ventilation scheme and end portal conditions.

\section{ANALYSIS OF RESULTS}

Based on previous explanations about boundary conditions and ventilation schemes, shown in Fig. 3, numerical results are presented over the 'Measure line', located as indicated in Fig. 3.

\section{Smoke propagation without emergency ventilation}

As for comparison purposes, it is considered firstly the scenario in which the ventilation systems would not work. In other words, the condition for which the smoke propagation is only driven by its natural convection.

Figure 5 depicts the longitudinal profile of smoke concentration over the "Measure line" at six different times from the beginning of the fire.

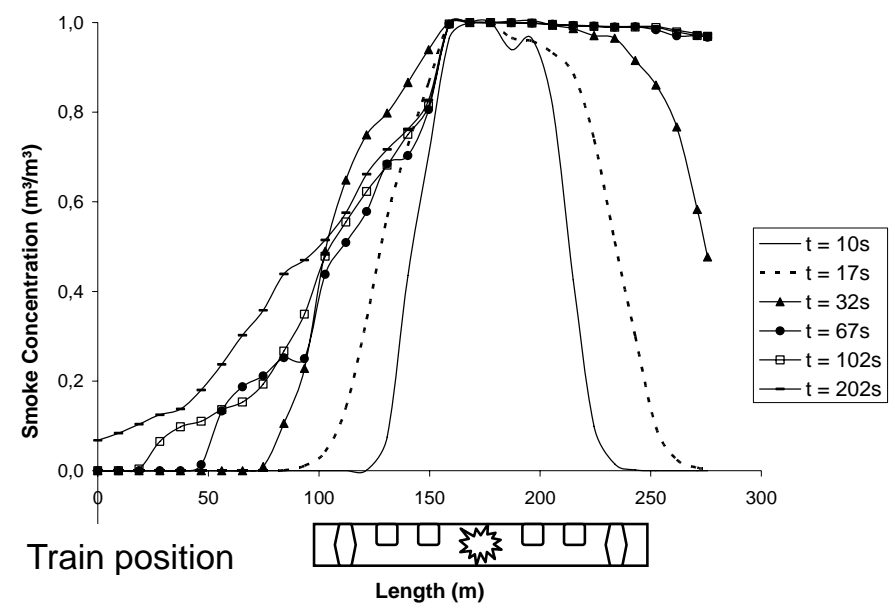

Figure 5. Longitudinal profile of smoke above the escape floor. Without Ventilation.

It can be seen that, at the end of the first $32 \mathrm{~s}$, the smoke cloud starts to grow in both directions, but suddenly it stops in the direction of Nuevo Circo station and keeps growing only towards Teatros station. Apparently, the smoke cloud stops because the effect of buoyancy and the slope of the tunnel. The smoke cloud has high toxicity and it directly affects the entire tunnel in the Teatros direction which, after less than 4 minutes (202 s) appears full of smoke.
Due to the lack of ventilation, the temperature profile, shown in Fig. 6 and 7, expands at large distances in a short time, while the profile shows the same asymmetrical behavior observed in the smoke cloud, between both stations. The analogous behavior between temperature and smoke concentration is easily understood, since both variables are represented in very similar transport equations, with differences only in the molecular diffusivity and boundary settings.

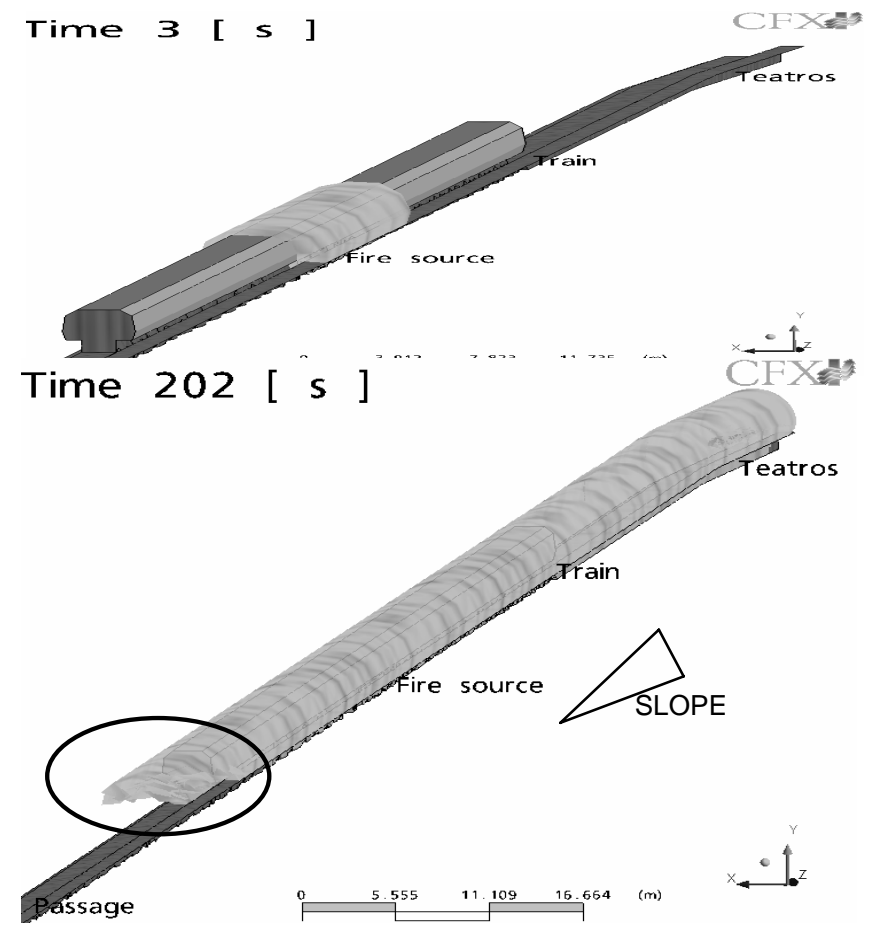

Figure 6. Smoke stack near the passage at $202 \mathrm{~s}$, showing the train under smoke

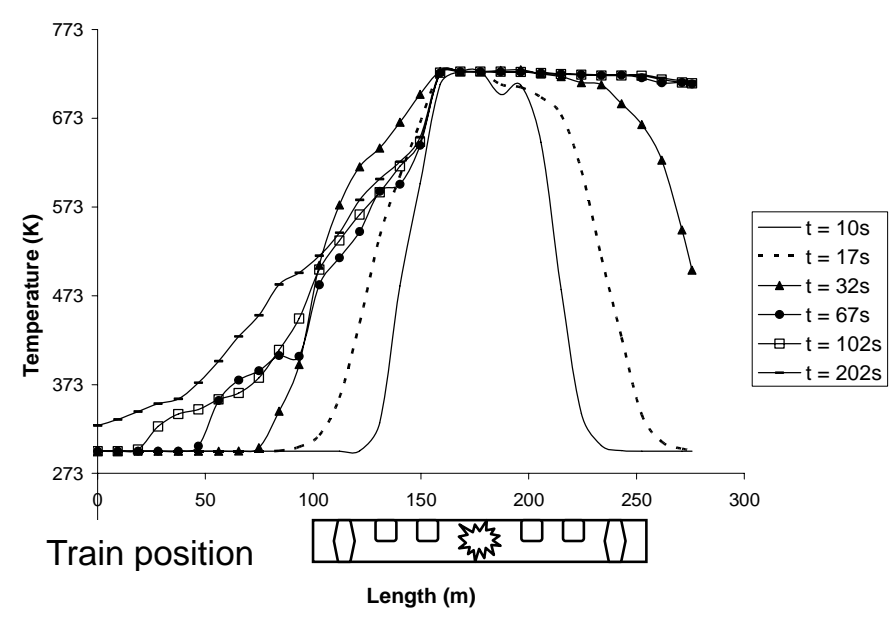

Figure 7. Longitudinal profile of temperature without ventilation 
Fire situation with emergency ventilation for $25 \%$ of mass flow exiting through Teatros station opening

In Fig. 8 , it is possible to notice the strong effect of the ventilation. In the first $10 \mathrm{~s}$, the ventilation starts transporting the smoke towards Nuevo Circo station. It is also notorious the rapidly increasing temperature due to the presence of fire. In fact, at $10 \mathrm{~s}$, around the fire source, the temperature reaches nearly $500 \mathrm{~K}$, which is about $30 \%$ less than what is found at the same time without ventilation (i.e., with only natural convection).

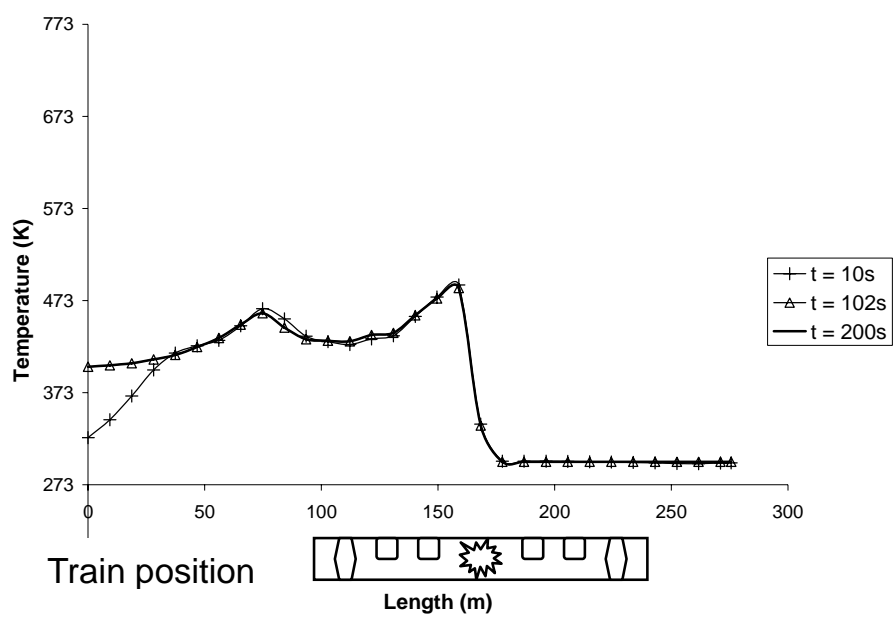

Figure 8. Longitudinal profile of temperature with $\mathbf{2 5 \%}$ of mass flow exiting through Teatros.

Figure 9 shows how the smoke concentration profile is dramatically lowered by the ventilation, compared to the case without ventilation. The highest level of concentration is around $0,45 \mathrm{~m}^{3} / \mathrm{m}^{3}$ (450000ppm), located very close to the fire source. Because of the ventilation system, the smoke concentration stabilizes in time and remains approximately constant after the first 200s. The efficiency shows that the ventilation system needs to be boosted since it still allows a substantial amount of smoke towards Nuevo Circo station, as shown in percentage values in Table 4.

It is important to remark that the highest concentration of smoke, along the "Measure line" represents 450000ppm, which is significantly dangerous in comparison with $3000 \mathrm{ppm}$ that is the deadly level in a time exposure of $30 \mathrm{~min}$ [10]. Thus, the passengers have very little time to evacuate the train and the tunnel if they try to escape in Nuevo Circo direction. Therefore, despite the ventilation influence, the escape in Nuevo Circo direction is inappropriate for the evacuation of passengers, due to the high temperature and smoke concentration.

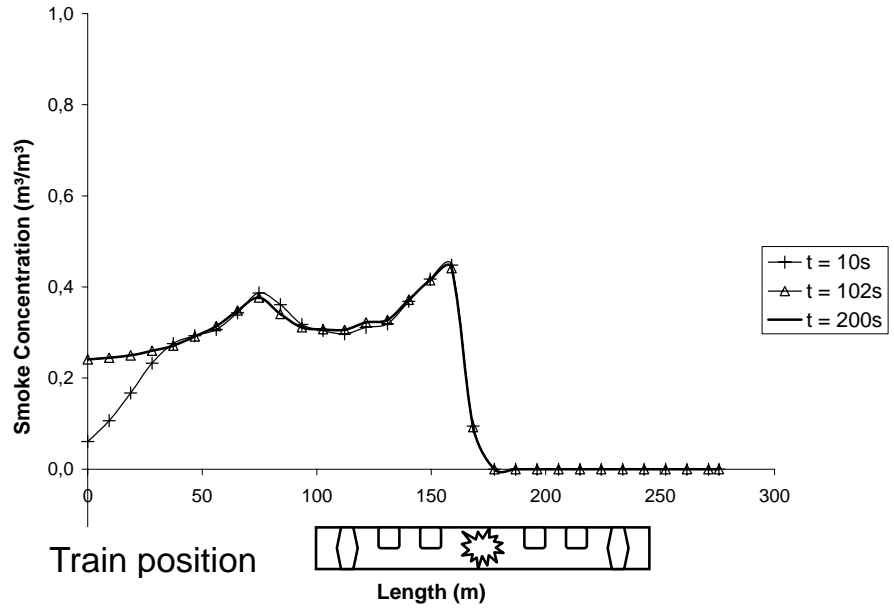

Figure 9. Longitudinal profile of smoke with $25 \%$ of mass flow exiting through Teatros.

Table 4. Efficiency of the ventilation system for $25 \%$ mass flow exiting through Teatros.

\begin{tabular}{|c|c|}
\hline Percentage of smoke respect to source & $\mathbf{\%}$ \\
\hline Efficiency of the ventilation system & 55,54 \\
\hline Passage & 9 \\
\hline Nuevo Circo station & 36 \\
\hline
\end{tabular}

Fire situation with emergency ventilation for $50 \%$ of mass flow exiting through Teatros opening.

At a larger fraction of air stream derived to Teatros station, as shown in previous profiles, the smoke concentration does not change much between the first $10 \mathrm{~s}$ and $200 \mathrm{~s}$. Figure 10 depicts an appreciably larger temperature of $600 \mathrm{~K}$ around the fire source. This occurs because the larger amount of air being sent to Teatros station.

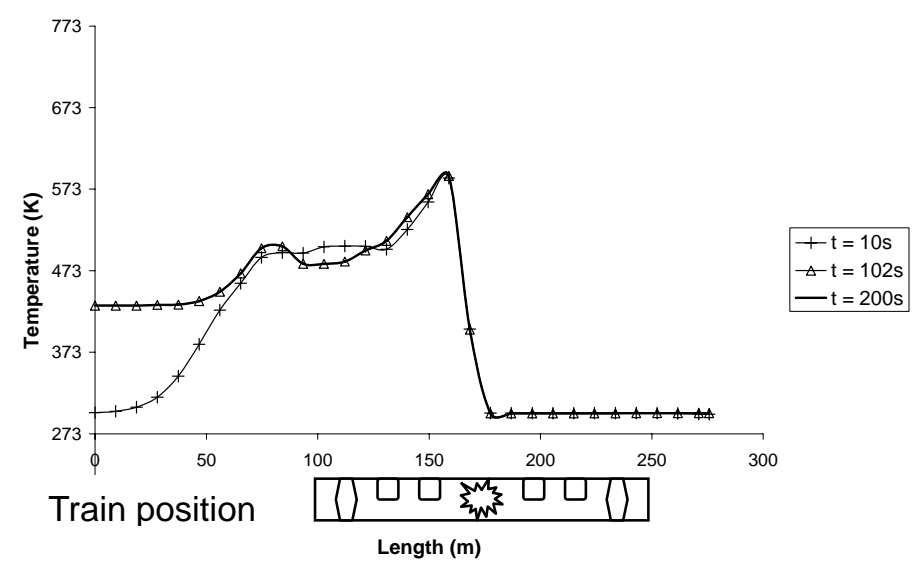

Figure 10. Longitudinal profile of temperature with $\mathbf{5 0 \%}$ of mass flow outlet by Teatros. 
Furthermore, for this case, it can be seen in Fig. 11 that the concentration of the smoke in the tunnel has increased accordingly. The maximum smoke concentration along the "Measure line" reaches $0,3 \mathrm{~m}^{3} / \mathrm{m}^{3}$ (300000ppm).

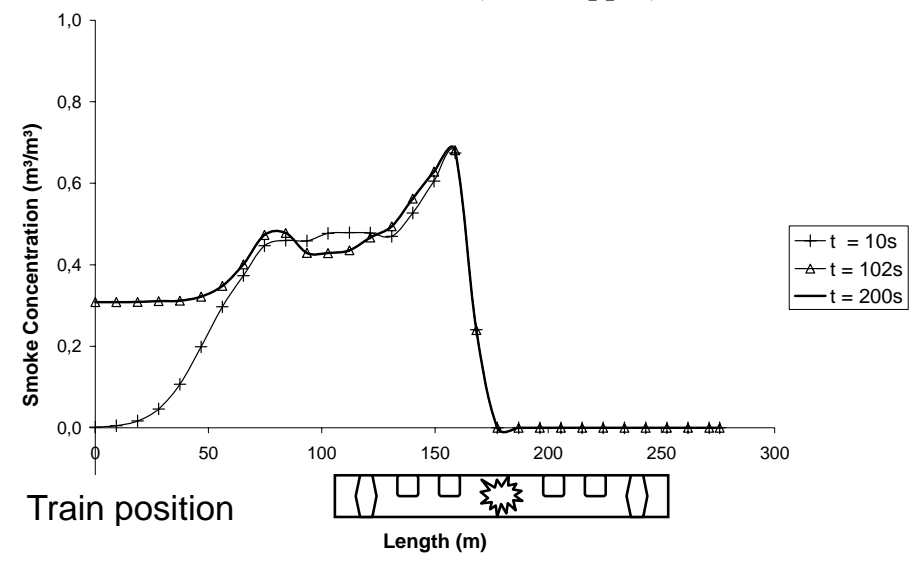

Figure 11. Longitudinal profile of smoke for $50 \%$ of mass flow exiting through Teatros.

The table 5 shows that the efficiency of the ventilation system is increased with respect to the first case because the inertia created by the ventilation is smaller and it allowed the exhaust fans to remove much more smoke. For the same reason the percentage of smoke in the passage has increased.

Table 5. Efficiency of the ventilations system for $50 \%$ of mass flow through Teatros opening

\begin{tabular}{|c|c|}
\hline Percentage of smoke respect to source & $\mathbf{\%}$ \\
\hline System ventilation efficiency & 63,64 \\
\hline Passage & 12 \\
\hline Nuevo Circo station & 24 \\
\hline
\end{tabular}

Fire situation with emergency ventilation with $75 \%$ of mass flow through Teatros opening.

Finally, for a larger air flow derivation towards Teatros station $(75 \%)$, as compared with previous cases, the smoke concentration profile does not change from the first $10 \mathrm{~s}$ to 200s. Figure 12 permits to appreciate the larger temperature of $700 \mathrm{~K}$ reached around the fire source, due to the deficit in air flow through the tunnel.

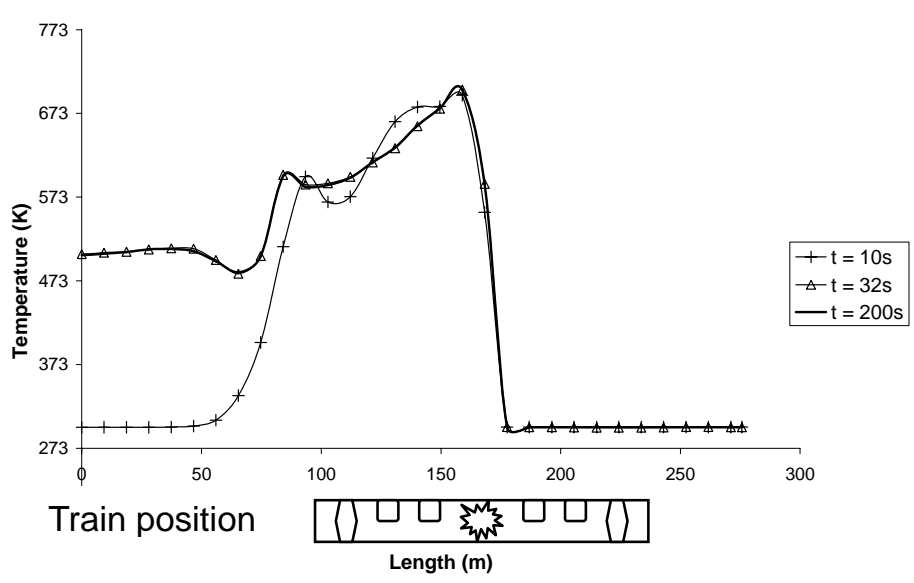

Figure 12. Longitudinal profile of temperature with $75 \%$ of mass flow through Teatros.

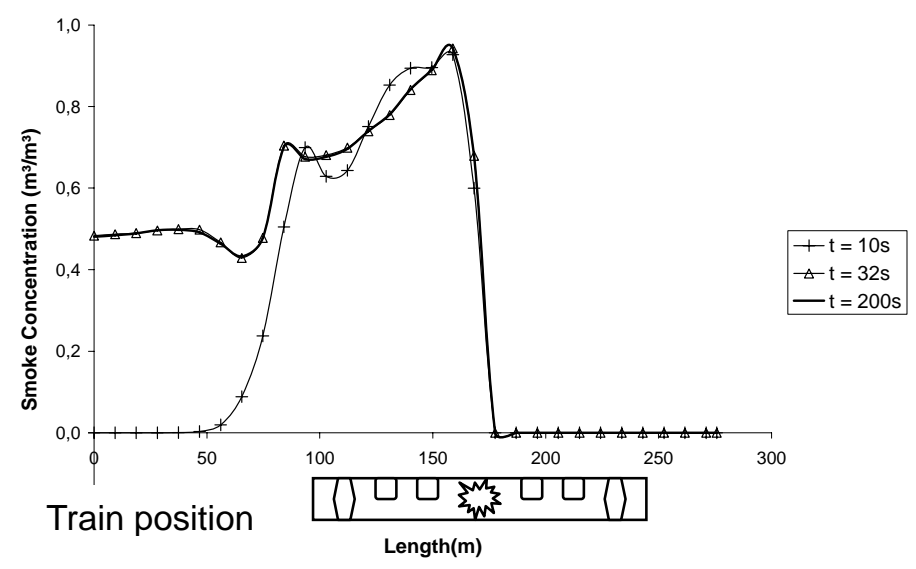

Figure 13. Longitudinal profile of smoke with $75 \%$ of mass flow through Teatros.

Figure 13 shows that the profile of smoke concentration is enhanced compared to the first cases. The larger levels of concentration are reached around $0,9 \mathrm{~m}^{3} / \mathrm{m}^{3}$ (900000ppm), which as usual, appeared close to the fire source. The value of smoke concentration along the "Measure line" looks larger as the lack of air flow affects the smoke removal and transport. Table 6 shows a remarkable drop in the smoke extraction efficiency, in agreement with the lack of air streaming through the tunnel.

Table 6. Efficiency of the ventilations system for $75 \%$ of mass flow through Teatros.

\begin{tabular}{|c|c|}
\hline Percentage of smoke respect to source & \% \\
\hline System ventilation efficiency & 52 \\
\hline Passage & 26 \\
\hline Nuevo Circo station & 22 \\
\hline
\end{tabular}


All the conditions evaluated, in general, show that the current ventilation system is able to drag around half of the total smoke being generated, allowing to escape the rest through the Nuevo Circo station and the passage located in the middle of the tunnel. The ventilation succesfully lowers the concentration of smoke, while sending the major quantity of air through the tunnel. All the simulations demonstrated that the ventilation system is capable to keep clear $(0 \%$ of smoke) the escape route to Teatros. But also, results have proven that the escape route to Nuevo Circo or to the mid-passage is compromised because, in the best cases, the concentration of smoke did not lower $0,45 \mathrm{~m}^{3} / \mathrm{m}^{3}$ (450000ppm) of smoke in air. It means that a person would not have chance to reach the exit because the toxicity of the enviroment during the evacuation. In the temperature profiles of all simulations, it is remarkable that between the fire source and Teatros station, the temperature is kept around $25{ }^{\circ} \mathrm{C}(298 \mathrm{~K})$ which helps the people to evacuate safely and it makes a secure passway for the firefighters team. On the other hand, for the route between the fire and the passage, the lowest temperatures were registered in the simulation with $25 \%$ of air mass flow derived towards Teatros station. However, the temperature in the evacuation route towards Nuevo Circo reached $127^{\circ} \mathrm{C}$ and it looks too high according to the recommendation of the NFPA that suggests $60^{\circ} \mathrm{C}(333 \mathrm{~K})$ as maximum temperature for the evacuation route. The lowest velocity of the air stream in the evacuation route towards Teatros is around $5 \mathrm{~m} / \mathrm{s}$, and was found in the simulation of $75 \%$ of air derived to Teatros station. That velocity is in good agreement with the suggestion of NFPA, which recommends it to be under $11 \mathrm{~m} / \mathrm{s}$, although there are very few points, like at the entrance of the ventilation room of Teatros in which the speed reached the $11 \mathrm{~m} / \mathrm{s}$ limit.

\section{CONCLUDING REMARKS}

The numerical simulation, based on the finite volume method, of the smoke propagation in the event of a fire within a subway tunnel is presented. The numerical tool proved to be capable to reproduce, within $10 \%$ of uncertainty, experimental data obtained from a benchmark tunnel. For the subway tunnel simulation, the qualitative features of the phenomenon appeared well described, proving the suitability of the tool for engineering purposes.

The ventilation system under the studied conditions was able to contain and transport the smoke in the tunnel while keeping Teatros station clean and as a safe evacuation route.

Current emergency and evacuation plans must be reviewed in order to consider the results from this investigation. However, it is strongly recommended to perform field measurements of the existing ventilation conditions to refine the input data for the model.

\section{ACKNOWLEDGMENTS}

The authors want to acknowledge the financial support by Hilti Venezuela; their generosity permitted to fund this investigation. Special thanks to Metro de Caracas Safety Dept. for their interest and for sharing all the valuable information and thorough discussions of scenarios during the course of the research.

\section{REFERENCES}

1. Vauquelin O. \& Mégret O., 2002, Smoke extraction experiment in case of fire in a tunnel, Fire Safety Journal, $37,525-533$.

2. Vauquelin O. \& Telle D., 2005, Definition and experimental evaluation of the smoke "confinement velocity” in tunnel fires, Fire Safety Journal, 40, 320-330.

3. Vauquelin O.\& Wu Y., 2006, Influence of tunnel with on longitudinal on smoke control, Fire Safety Journal, 41, 420-426.

4. Hasib R., Kumar R., Shashi and Kumar S., 2007, Simulation of an experimental compartment fire by CFD, Building and Environment, 42, 3149-3160.

5. Tarada F., 2000, Critical Velocity for Smoke Control in Tunnel Cross-Passage, First International Conference on Major Tunnel and Infrastructure Projects.

6. Abantos J., Reggio M., Barrero D. and Petro E., 2006, Prediction of fire and smoke propagation in an underwater tunnel, Tunnelling and Underground Space Technology, 22, 90-95.

7. Bari S. \& Naser J., 2005, Simulation of smoke of a burning vehicle and pollution levels caused by traffic jam in a road tunnel, Tunnelling and Underground Space Technology, 20, 281-290.

8. Kashef A., Bènichou N. and Lougheed G., 2003, Numerical Modelling of Movement and Behaviour of Smoke Produced from Fires in the Vill-Marie and L.-H.La Fontaine Tunnels: Literature Review, Institute for Research in Construction.

9. Liu Z., Kashef A., Crampton G., Lougheed G. and Almand K., 2007, Research progress of the international road tunnel fire detection project, $4^{\text {th }}$ International Conference on Traffic and Safety in Roads Tunnels, 1-13.

10. Galdo-Vega M., Ballesteros-Tajadura R. and SantolariaMorros C., 2006, NUMERICAL 3D SIMULATION OF A LONGITUDINAL VENTILATION SYSTEM: MEMORIAL TUNNEL CASE, 2006 ASME Joint U.S.European Fluids Engineering Summer Meeting.

11. Vittori F., 2008, NUMERICAL STUDY OF SMOKE PROPAGATION IN A SIMULATED FIRE IN A WAGON WITHIN A SUBWAY TUNNEL, Universidad Simón Bolívar. 